\title{
Synthesis of Ag-Pt alloy nanoparticles in aqueous bovine serum albumin foam and their cytocompatibility against human gingival fibroblasts
}

\author{
A.V. Singh ${ }^{\mathrm{a}, \mathrm{b}}$, R. Patil $^{\mathrm{b}}$, M.B. Kasture ${ }^{\mathrm{a}}$, W.N. Gade ${ }^{\mathrm{b}}$, B.L.V. Prasad ${ }^{\mathrm{a}, *}$ \\ a Materials Chemistry Division, National Chemical Laboratory, Pune 411008, India \\ ${ }^{\mathrm{b}}$ Department of Biotechnology, University of Pune, Ganesh Khind, Pune 411007, India
}

\section{A R T I C L E I N F O}

\section{Article history:}

Received 8 August 2008

Received in revised form 19 November 2008

Accepted 21 November 2008

Available online $\mathrm{xxx}$

\section{Keywords:}

Protein foams

Alloy nanoparticles

Biocompatibility

Human gingival fibroblasts

ELISA

mRNA

\begin{abstract}
A B S T R A C T
Foams of bovine serum albumin (BSA) have been utilized for synthesizing in situ protein capped Ag-Pt alloy nanoparticles. The in vitro cytotoxicity and the rate of proliferation of human gingival fibroblasts (HGFs) in presence of the above synthesized alloy nanoparticles is investigated. Expression profile of protein involved in detoxification, i.e. metallotheonein (MT) were assayed by ELISA and expression of mRNA transcripts by reverse transcription polymerase chain reaction (RT-PCR). Cytotoxicity results suggested that protein capped nano-alloys might be promising candidates for implants and prosthetic material. RT-PCR and ELISA confirmed the expression of MT, in cells treated with the alloy nanoparticles. Morphology variation studied by SEM also confirms that cells treated with alloy nanoparticles present an intact morphology.
\end{abstract}

(c) 2008 Elsevier B.V. All rights reserved.

\section{Introduction}

Designing new synthetic protocols for nanoscale biocompatible materials is currently receiving considerable attention. Interest in nanomaterials arises due to new properties and functions stemming from their dimension and modified electronic structure [1]. Among various nanomaterials, with respect to biomedical applications, much attention had been paid towards alloy and composite materials for their superior properties compared to the individual components constituting the alloy/composite [2-5]. With respect to applications related to dentistry some nanoparticulate systems have crossed the realm of researchers and have gained entry to the market also. Particular mention should be made of $\mathrm{Ag}-\mathrm{Cu}$ being used in dental implants and toothpastes that claim to contain nanoparticles which over a period of time fill up the cavities [6]. In the recent past Ag-Pt alloy nanoparticles (NPs) aroused much interest of researchers because of their novel application in dentistry, bone and breast surgical implants on account of their corrosion resistance and improved mechanical properties [7-9]. A key challenge to material scientists is to synthesize biocompatible Ag-Pt alloy NPs for their application in vivo that imposes stringent conditions of compatibility, non-immunogenecity, etc. A

\footnotetext{
* Corresponding author. Tel.: +91 20 25902013; fax: +91 2025902636.

E-mail addresses: wngade@unipune.ernet.in (W.N. Gade), pl.bhagavatula@ncl.res.in (B.L.V. Prasad).
}

strategy towards such biocompatibility is to conjugate biocompatible, non-immunogenic protein molecules to the alloy NPs. While post-synthetic conjugation is a possibility, a much better alternative is to synthesize these materials in a template made-up of the protein of interest.

Bimetallic colloids can be prepared by simultaneous coreduction of two kinds of metal ions with or without the protective agent (usually a polymer or a surfactant) or by successive reduction of one metal over the nuclei of another involving physical or chemical route [10-12]. Alloy systems are usually realized by the simultaneous reduction of the metal ions [13]. For example, for the chosen system here, i.e. Ag-Pt alloy the precursors of silver and platinum ions are taken together and subjected reduction concurrently. Usually the salt precursors used for silver are $\mathrm{Ag}^{+}$ions while those for platinum are $\mathrm{PtCl}_{6}{ }^{-}$ions. A stumbling block in this procedure is the resultant alloy NP's phase purity, i.e. to avoid the separate nucleation of the individual nanoparticles along with the alloy NPs. Traditional surfactants compound this problem, as these are normally either positively or negatively charged and preferentially bind to one of the ions and hence promote separate nucleation. A way to circumvent this problem is to achieve a thorough mixing of the metal ions that constitute the alloy at atomic scale and then subject them to reduction. Here we use the bovine serum albumin as a template and stabilizing agent, which is zwitterionic in nature at its pI. The zwitterionic nature is also favorable for its foaming and some of us have previously reported the advantages of using foams for obtaining phase pure alloy NPs [14]. In the case investi- 
gated here, the alloy formation is simply accomplished by carrying both $\mathrm{Ag}$ and Pt ions in BSA foam simultaneously and reduction of metal ions was achieved by passing vapors of hydrazine hydrate through the foam. It is observed that the silver ions get reduced with hydrazine hydrate, which reduces the platinum ions by transmetallation reaction due to their favorable redox potentials for a spontaneous reduction of $\mathrm{Pt}^{4+}$ by $\mathrm{Ag}^{0}$ [15]. At appropriate concentration of the two ions alloy formation occurs and since these are formed inside the foam matrix the resultant alloy NPs are in situ capped by the protein molecules.

Then, in order to probe the resultant alloy NPs biocompatibility, especially with dental applications in mind, we investigated the effect of the alloy NPs on proliferation and cytotoxicity on human gingival fibroblast (HGF) cells cultured in vitro. Our data indicate that formed alloy NPs are more tissue compatible with HGFs compared to the salt precursors $\left(\mathrm{Ag}_{2} \mathrm{SO}_{4}\right.$ and $\left.\mathrm{H}_{2} \mathrm{PtCl}_{6}\right)$ [16]. After ascertaining the alloy NPs nontoxic nature, we studied the events at molecular level by ELISA and RT-PCR to assess the mechanism involved in detoxification. It is well known that the expression of the protein MT and its presence in culture conditions is indicative of cell survival in spite of presence of salt [17]. In our study with alloy and silver salt precursors, MT expression is seen suggesting prima facie that BSA capping provides compatibility of NPs with the cells in vitro. SEM reveals that with salt precursors HGFs present loose cell morphology but remain intact in alloy environment, supporting their utility for in vivo applications. Details of studies carried out are presented below.

\section{Experimental}

\subsection{Chemicals}

Silver sulphate $\left(\mathrm{Ag}_{2} \mathrm{SO}_{4}\right)$, chloroplatinic acid $\left(\mathrm{H}_{2} \mathrm{PtCl}_{6}\right)$, and hydrazine hydrate $\left(\mathrm{N}_{2} \mathrm{H}_{4}\right)$, all were obtained from Aldrich chemicals and used as received. Bovine serum albumin (BSA 98\%, $66 \mathrm{kDa}$ mol. wt.) was obtained from SRL Chemicals, India Ltd. and used as received.

\subsection{Synthetic procedure}

In a typical experiment, a rectangular column of $50 \mathrm{~cm}$ in height and with a square base of $10 \mathrm{~cm} \times 10 \mathrm{~cm}$ with sintered frit embedded at the bottom was used for foam generation. $25 \mathrm{~mL}$ of $\mathrm{Ag}_{2} \mathrm{SO}_{4}$ $\left(1 \times 10^{-3} \mathrm{M}\right.$, that leads to a final concentration of $2 \times 10^{-3} \mathrm{M} \mathrm{Ag}^{+}$ in the final solution) and $25 \mathrm{~mL}$ of $\mathrm{H}_{2} \mathrm{PtCl}_{6}\left(3 \times 10^{-3} \mathrm{M}\right)$ were mixed and added to $50 \mathrm{~mL}$ bovine serum albumin (BSA) solution $(3 \mathrm{mg} / \mathrm{mL}$ ). The $\mathrm{pH}$ of the solution was adjusted to 4.7 which is the pI of BSA. The solution was taken in the bottom of foam column. Nitrogen gas was allowed to pass through the frit at the bottom of the foam column to generate the foam. The foam was allowed to raise into the column up to a height of $45 \mathrm{~cm}$ and the gas flow was stopped. The excess liquid from foam was drained for 20 min so that a dry foam condition is created. A Petridish containing hydrazine hydrate was kept under the foam column such that the vapors pass through foam and the reduction occurs. After 25 min of reaction, the color of foam column changes to grayish. The reduced alloy NPs in foam are collected by spraying water from the top of the foam column. The collected solution was centrifuged at $10,000 \mathrm{rpm}$ for $15 \mathrm{~min}$ for the separation of protein from the sample. The pellet sample was washed with distilled water and recentrifuged described as above for complete removal of uncapped protein from sample. The pellet sample was used for the further UV, XRD, TEM, XPS characterization, etc. We also tried to synthesize individual platinum and silver nanoparticles in BSA aqueous foam by same method as described above. In these cases a $50 \mathrm{~mL}$ solu- tions of $\mathrm{Ag}_{2} \mathrm{SO}_{4}$ or $\mathrm{H}_{2} \mathrm{PtCl}_{6}\left(1 \times 10^{-3} \mathrm{M}\right)$ were taken instead of the mixture. The reduction was observed only when silver ions alone were taken and with platinum alone no reduction took place.

\subsection{UV-vis spectroscopy studies}

The optical properties were monitored on a Jasco UV-vis spectrophotometer (V570 UV-VIS-NIR) operated at a resolution of $2 \mathrm{~nm}$.

\subsection{TEM measurements}

TEM samples were prepared by placing a few drops of their aqueous dispersions on carbon coated copper grids and allowing them to dry. TEM measurements were performed on a JEOL model 1200EX instrument operated at an accelerating voltage at $80 \mathrm{kV}$.

\subsection{X-ray diffraction measurements}

Thick films on glass substrate prepared from the aqueous solutions were used for this purpose. The samples were characterized on the X'pert Pro model X-ray diffractometer from PanAlytical instruments operated at a voltage of $40 \mathrm{kV}$ and a current of $30 \mathrm{~mA}$ with $\mathrm{Cu} \mathrm{K \alpha}$ radiation.

\subsection{XPS measurements}

XPS measurements of Ag-Pt alloy nanoparticles were carried on a film deposited onto copper substrate by the drop coating technique. VG Micro Tech ESCA 3000 instrument operating at a pressure better than $10^{-9}$ Torr was used. The general scan was performed and $\mathrm{C} 1 \mathrm{~s}, \mathrm{~N} 1 \mathrm{~s}, \mathrm{O} 1 \mathrm{~s}, \mathrm{~S} 1 \mathrm{~s}, \mathrm{Ag} 3 \mathrm{~d}$ and $\mathrm{Pt} 4 \mathrm{f}$ level spectra were recorded with un-monochromatized $\mathrm{Mg} \mathrm{K} \alpha$ radiation (photon energy = $1253.6 \mathrm{eV}$ ) at pass energy of $50 \mathrm{eV}$ and electron take off angle (angle between electron emission direction and surface plane) of $60^{\circ}$. The overall resolution of measurement is $1 \mathrm{eV}$ for the XPS measurements. The core level spectra were background corrected using the Shirley algorithm [18] and chemically distinct species were resolved using a nonlinear least square procedure. The core level binding energies (BEs) were aligned with respect to the $\mathrm{C} 1 \mathrm{~s}$ binding energy of $285 \mathrm{eV}$.

\subsection{Cytocompatibility test}

Human gingival fibroblasts (HGFs) were isolated from three patients under local anesthesia from normal skin (two males and one female from 18 to 35 years of age) with their informed consent without any history of oral pathology. Proper Ethical Cleavances were taken from appropriate authorities. Before culture, the samples were rinsed with phosphate-buffered saline (PBS), and deep dermal layers and necrotic tissues were removed. Tissue were cut into small fragments by sterilized scalpel and then transferred to Petridishes containing $20 \mathrm{~mL}$ dispases $(20 \mathrm{mg} / \mathrm{mL})$. Tissue pieces were again rinsed with PBS and further minced with scalpel in order to loosen the tissue matrix and facilitate the migration of fibroblast into the medium. HGFs were next isolated from tissue pieces by overnight digestion with Type I collagenase $(80 \mathrm{U} / \mathrm{mL}$, Worthington Biochemical Corporation, Freehold, NJ) with Dulbecco modified Eagles media [DMEM] containing 20\% fetal calf serum (FCS from Gibco BRL, Carlsbad, CA) at $37^{\circ} \mathrm{C}$ and plated in $75 \mathrm{~cm}^{2}$ plastic culture flask. Now fibroblast were further propagated in DMEM supplemented with $10 \%$ FCS, penicillin and streptomycin [100 $\mu \mathrm{g} / \mathrm{mL}$ each, Gibco Invitrogen Corporation], and amphotericin $\mathrm{B}$ [2 ng/mL Gibco] under standard culture conditions (i.e. at $37^{\circ} \mathrm{C}$ in a humidified atmosphere containing $5 \% \mathrm{CO}_{2}$ ) and cell culture medium were changed regularly at an interval of every $48 \mathrm{~h}$. After attaining $80 \%$ confluence, cells were trypsinized and passaged into $1: 3$ split ratios. After first passage, cells were routinely maintained 
in 10\% FCS-DMEM during a week. For the cell culture studies, HGFs were used after $4-5$ th passage.

\subsection{RNA extraction and reverse transcription polymerase chain reaction $(R T-P C R)$}

For determination of metallotheonein (MT) expression in response to metal toxicity, HGFs were seeded at density of $5 \times 10^{5}$ cells/well in six well culture plates and incubated overnight. Cells were treated separately at 50 and $100 \mu \mathrm{M}$ concentrations for $\mathrm{Ag}_{2} \mathrm{SO}_{4}, \mathrm{H}_{2} \mathrm{PtCl}_{6}$ and $\mathrm{Ag}-\mathrm{Pt}$ alloy NPs for next $24 \mathrm{~h}$. Untreated cells were taken as standard control for RT-PCR. Total RNA was extracted from control cells and treated cells with NPs and salt precursor using Triazol methods (Invitrogen, Carlsbad, CA) and purification columns (RN easy, Quiagen, Valencia, CA). After DNAse I treatment, reverse transcription of $2 \mu \mathrm{g}$ of RNA from different samples including control were incubated with random primer, $0.1 \mu \mathrm{M}$ oligo $(\mathrm{dT})$ primer (Clonetech), $500 \mu \mathrm{M}$ dNTPs and 200 units of MMLV reverse transcriptase (Life technologies) at $37^{\circ} \mathrm{C}$ for $1 \mathrm{~h}$. This was followed by incubation for $5 \mathrm{~min}$ at $95^{\circ} \mathrm{C}$ in the presence of RNase inhibitors to avoid RNA contamination from previous step and to ensure cDNA to be amplified following PCR reactions. The PCR reaction was performed from the transcripts obtained after cDNA synthesis from each sample including control using recombinant Taq polymerase (Life technologies) with forward primer sequence $5^{\prime}$ ATGGATCCCAACAACTGCTCCTGCG-3' and reverse primer sequence 5'-AGGGCTGTCCCAACATCAGGC-3' under following PCR reaction conditions: denaturation at $94{ }^{\circ} \mathrm{C}$ for $1 \mathrm{~min}$, annealing at $62{ }^{\circ} \mathrm{C}$ for $1 \mathrm{~min}$ and extension at $72^{\circ} \mathrm{C}$ for $1 \mathrm{~min}$. After 30 cycles, there was a final extension at $72{ }^{\circ} \mathrm{C}$ for $10 \mathrm{~min}$. $\beta$-Actin was used as loading control with $5^{\prime}$-TGGAATCCTGTGGCATCCA-3' as forward primer and 5'-TAACAGTCCGCCTAGAAGCA-3' as reverse primer.

\subsection{Enzyme linked immunosorbent assay (ELISA)}

HGFs cells were seeded in six well plates over night at seeding density of $5 \times 10^{5}$ cells/well and subsequently treated with same concentration as mentioned above for cytocompatibility test with salt precursors and alloy NPs for $24 \mathrm{~h}$. Untreated cells served as standard control for MT expression profile. All culture samples exposed to metal salt precursors and alloy NPs as mentioned above were assayed for MT secretion using sandwich ELISA. Fisher plates were coated with goat-anti-mouse Fab antibody and nonspecific sites were blocked with BSA $(30 \mathrm{~g} / \mathrm{L})$ and sodium azide ( $3 \mathrm{mmol} / \mathrm{L})$. Unbound BSA was washed with PBS and monoclonal anti-human metallotheonein-1 and -2 were added in 1:600 ratio and incubated for $2 \mathrm{~h}$. Plates were washed with washing buffer and $100 \mu \mathrm{L}$ purified metallotheonein from cells incubated with different salt precursor and alloy NPs were added. After brief incubation washed and biotinylated chicken anti-human metallotheonein IgY in a 1:1000 was added to this and further incubated for $2 \mathrm{~h}$. Later plates were washed and avidin/alkaline phosphatase conjugate (Sigma Chemicals) was added in dilution of 1:4000 and incubated for an hour. Plates were washed and p-nitro phenyl phosphate was added and after incubation, absorbance was recorded at $405 \mathrm{~nm}$.

\subsection{Proliferation assay}

Assay was performed during 7-day span. Seven sets of six well plates with seeding density as mentioned above were scheduled to study at the rate of one set of plate each day. Cells from each plate after schedule time of study were gently rinsed with PBS and treated with $0.1 \%$ collagenase in $300 \mu \mathrm{L}$ of $0.25 \%$ trypsin and $1 \mathrm{mM}$ EDTA at $37^{\circ} \mathrm{C}$ for $15 \mathrm{~min}$. A Neubar's chamber was used to count the detached cells and selected surface were carefully observed under microscope in order to assure that no cells remain attached at selected surface.

\subsection{SEM analysis}

Cell morphology and surface integrity of those exposed to salt precursors and alloy NPs were studied by Leica Stereoscan-440 scanning electron microscope (SEM) equipped with a Phoenix EDAX attachment.

\section{Results and discussions}

\subsection{Chemical characterization}

The general process for synthesis of nanomaterials in foam matrix involves the electrostatic complexation of metal ions with oppositely charged surfactant molecules, followed by the foam generation and subsequent in situ chemical reaction appropriate for the desired material. BSA imparts greater flexibility to this method by allowing the complexation of metal ions with opposite charges simultaneously at its isoelectric point. BSA along with albumin and casein are also known to be some of the best foaming [19] proteins. We found that stable foam could be obtained when both $\mathrm{Ag}^{+}$and $\mathrm{PtCl}_{6}{ }^{-}$ions are taken simultaneously or separately in the BSA aqueous mixture. The formation of metal alloy nanoparticle by action of hydrazine in aqueous foam of BSA can be easily proved by the combination of optical absorbance, TEM, XRD and selected area electron diffraction patterns.

We have observed that the platinum ions are not reduced by hydrazine hydrate in BSA aqueous foam while silver ions get easily reduced [14]. More specifically, when silver ions alone are present in the foam matrix hydrazine exposure leads to yellow color formation [14]. In contrast, no color change is observed when similar experiment is carried out with $\mathrm{Pt}^{4+}$ ions immobilized in the foam matrix. XRD measurements carried on the solution after rupturing the foam matrix did not reveal any discernible peaks supporting this claim. Thus, we can conclude that hydrazine vapors are not capable of reducing $\mathrm{Pt}^{4+}$ while they can reduce $\mathrm{Ag}^{+}$to $\mathrm{Ag}^{0}$. Most interestingly, when silver and platinum salts were carried into the BSA foam matrix simultaneously and allowed to react with hydrazine hydrate vapors, the colorless foam matrix turned to dark grayish. The nature of nanoparticles formed when $\mathrm{Ag}^{+}$and $\mathrm{Pt}^{4+}$ ions are simultaneously taken was characterized by UV-vis, XRD and TEM techniques and are described in the following. First, the optical spectra for $\mathrm{Ag}-\mathrm{Pt}$ alloy NPs are shown in Fig. 1A along with the spectrum of silver nanoparticles alone produced under similar conditions to those of alloy NPs. The silver nanoparticles alone display a peak at $418 \mathrm{~nm}$ (curve 1) while for Ag-Pt alloy NPs a peak at $400 \mathrm{~nm}$ (curve 2) is observed. Aqueous dispersions of silver nanoparticles are known to absorb in the vicinity of $420 \mathrm{~nm}$ [20], while platinum particles show only a monotonous increase in absorbance as the wavelength decreases [21]. It is known in the literature that in the alloy NPs of two metals a peak in absorbance is observed between those of the individual nanoparticles [13]. Thus, the clear blue shift in curve 2 with respect to silver NPs suggests the formation of alloy NPs by optical characterization [22]. These alloy dispersions were allowed to reflux for few min. Refluxing is known to facilitate alloy nanoparticles formation even if there are few individual nanoparticles [23]. The absorbance curve after reflux shows further blue shift and a narrower peak compared to as synthesized alloy NPs (Fig. 1A, curve 3 ). The narrow peak may indicate a narrower size distribution (vide infra) and the blue shift suggests a better alloy formation. For further confirmation of alloy formation, the X-ray diffraction characterization for silver (curve 1) and silver platinum alloy NPs (curve 2) were carried out and results are shown in Fig. 1B. Pure silver NPs show 

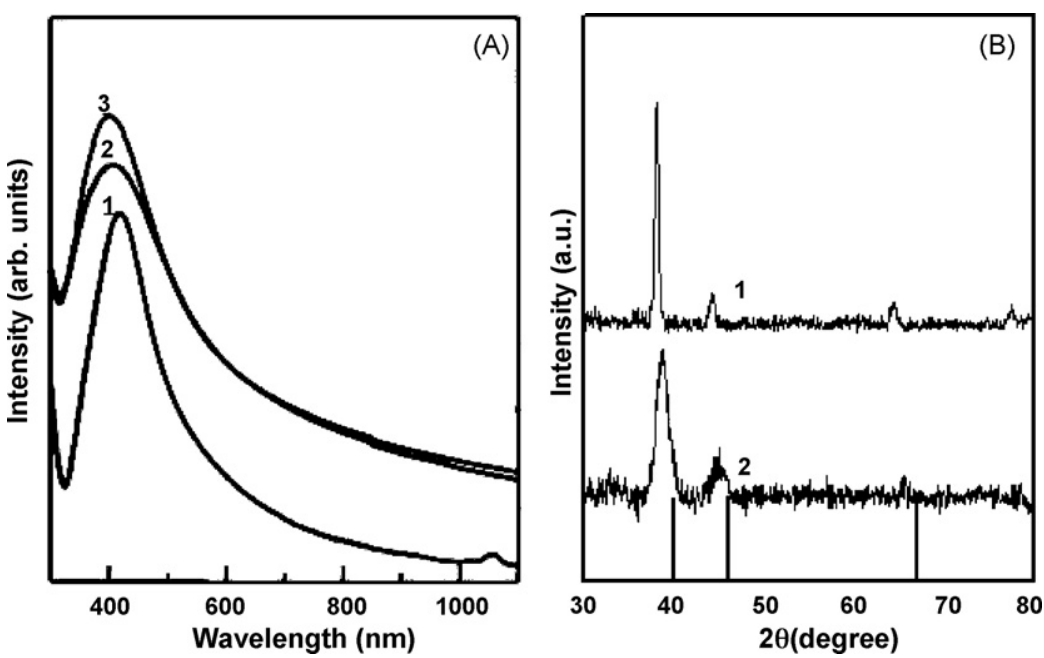

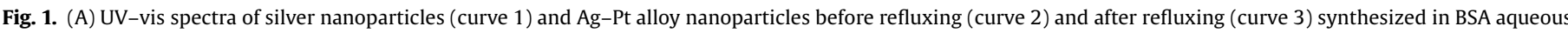

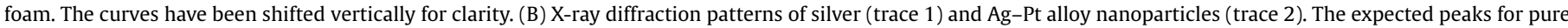
Pt are shown as vertical lines.

two strong scattering peaks at $d$ values $\sim 2.37$ and $\sim 2.05 \AA$ that can be assigned to the (111) and (222) planes respectively (JCPDS 040783). The reported $d$ values for fcc phase pure Pt are 2.26 and $1.96 \AA$ that are shown as vertical lines in Fig. 1B (JCPDS 04-0802). Ag-Pt alloy NPs (curve 2 ) show two peaks, a sharp peak corresponding to the $d$ value $2.33 \AA$ and another broad peak at $2.03 \AA$. However, the peaks at 2.33 and $2.03 \AA$ that are in between those corresponding to pure silver and pure platinum strongly supporting the alloy formation [22] and are in full accordance with Vegards law [24]. The $\mathrm{Ag}-\mathrm{Pt}$ alloy formation observed here could be happening via a different mechanism as compared to the previously reported $\mathrm{Au}-\mathrm{Ag}$ alloy formation [14]. From the sequence of events it can be deduced that the silver ions are first reduced to $\mathrm{Ag}^{0}$ which in turn reduce the $\mathrm{Pt}^{4+}$ ion, through a galvanic exchange reaction [15]. The reasons for the requirement of higher platinum as compared to the silver ions is not clear at this moment. One possible reason is that silver ions bind to BSA little better than Pt ions through thiol containing amino acids and also owing to their smaller size necessitating higher platinum concentrations for better alloy formation. We hasten to add here that these are intuitive explanations and better studies are needed to substantiate them further.

Further, the alloy NPs were subjected to TEM characterization. The resulting TEM micrographs are shown in Fig. 2A and B indicating that the NPs are mostly polydisperse in nature with an average size of $10-15 \mathrm{~nm}$ and few alloy particles tends to from irregular aggregates evident as larger particles in TEM images (Fig. 2B). Inset in Fig. 2B shows selected area electron diffraction (SAED) that can be indexed to $111,200,220$, and 311 planes appearing from Bragg reflections of the alloy. The diffuse ring pattern in SAED suggests that formed alloy NPs is polycrystalline in nature. The TEM micrographs (Fig. 2C and D) observed from the samples subjected to reflux show the formation of spherical particle with a slightly narrower size distribution as compared to as prepared sample. The relative size and shape uniformity in the refluxed sample explains the narrower and more defined peak (Fig. 1A, curve 3) in the optical spectra. The selected area electron diffraction for these sample again showed diffraction corresponding to the planes $(111,200$, 220 , and 311 ; as shown in inset of Fig. 2D) and strongly indicate that there is no significant change in crystal pattern of alloy NPs upon heating. The spot pattern observed suggests increased crystallinity upon refluxing.

Auxiliary confirmation for the presence of metals in the reduced state comes from X-ray photoelectron spectroscopy. The pellet sam- ple was drop coated on copper strip and the core level spectra's were recorded. The Ag 3d core level spectrum is shown in Fig. 3A while the Pt $4 \mathrm{f}$ core level spectrum is shown in Fig. 3B. The general spectra of the above sample was also recorded and showed the presence of $\mathrm{C} 1 \mathrm{~s}, \mathrm{~N} 1 \mathrm{~s}, \mathrm{~S} 2 \mathrm{p}, \mathrm{O} 1 \mathrm{~s}$, core level spectra. The charging correction in all the core level spectra were effected by taking the $C 1 \mathrm{~s}$ binding energy to be $285 \mathrm{eV}$. The spectra in Fig. 3(B) could be deconvoluted in to two-spin-orbit pairs one corresponding to Pt $4 \mathrm{f}_{7 / 2}$ (BE $72.1 \mathrm{eV}$ and spin-orbit coupling $3.35 \mathrm{eV}$ ) characteristic of Pt in the sample and the other corresponding to $\mathrm{Cu} 3 \mathrm{p}_{3 / 2}$ (BE $76.6 \mathrm{eV}$ and spin-orbit coupling $2 \mathrm{eV}$ ) that could be coming from substrate. The $\mathrm{Ag} 3 \mathrm{~d}$ core level spectrum could be resolved into a single spin orbit (spin-orbit splitting $6 \mathrm{eV}$ ) with $3 \mathrm{~d}_{5 / 2}$ BE of $368.2 \mathrm{eV}$ (Fig. $3 \mathrm{~A}$ ). This $\mathrm{BE}$ is characteristic of $\mathrm{Ag}$ in fully reduced state. The fact that the spectrum could be deconvoluted into a single spin-orbit pair indicates the complete reduction of Ag ions by the hydrazine. Above observations recorded in XPS are in good agreement with reported values [25].

\subsection{Cytotoxicity studies in vitro}

Biomedical applications of noble metal nano-alloys necessitate their cytocompatiblity and capacity to restore natural morphology of the tissue in contact without triggering immunogenecity and alteration of tissue morphology. Therefore, prior to in vivo applications, an in vitro method to evaluate cytocompatibility is a prerequisite. In order to deduce the biological applications of $\mathrm{Ag}-\mathrm{Pt}$ alloys, we studied proliferation kinetics and viability of cells exposed to alloy NPs at different concentrations. In addition how the present alloy effects the cell shape and morphology were evaluated by SEM. The purpose of aforementioned studies was to make a case for the usage of synthesized alloy for dental and prosthetic applications.

MTT [3-(4,5-dimethylthiazoyl-2-yl)-2,5-diphenyltetrazolium bromide] assay is used to demonstrate the viability of cells through the reduction of the pale yellow MTT dye to a dark blue formazan product by the activity of succinate dehydrogenase present in the mitochondria of living cells. The amount of formazan formed is thus directly correlated to the number of living cells present and is recorded as an absorbance at $570 \mathrm{~nm}$ by dissolving the formed produced in a suitable organic solvent [26]. The results of the cytotoxicity of Ag, Pt salt precursors and Ag-Pt alloy nanoparticles for HGF cells are shown in Fig. 4A. Untreated and cells treated with only BSA served as control experiments. After $48 \mathrm{~h}$ of treatment, 

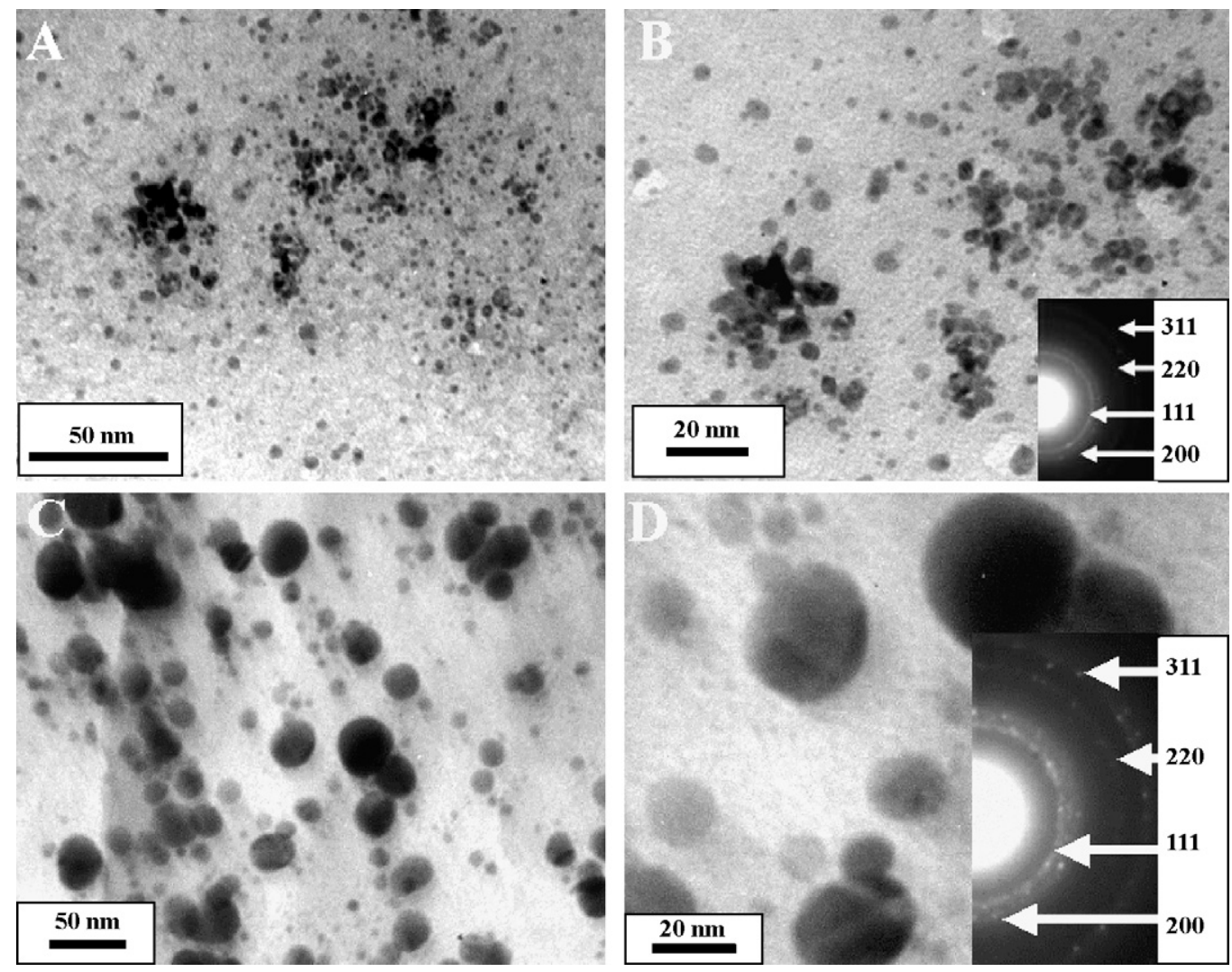

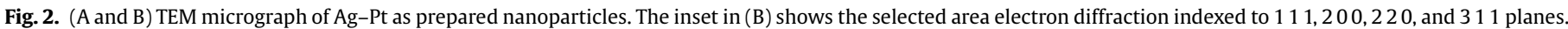

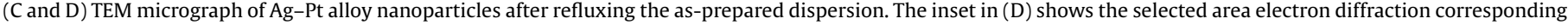
to the alloy phase and indexed to $111,200,220$, and 311 planes.

cells exposed to $50 \mu \mathrm{M}$ silver salt show more than $75 \%$ cell viability where as $100 \mu \mathrm{M}$ salt reduces viability to $\sim 15 \%$, suggesting that silver salt beyond $50 \mu \mathrm{M}$ concentration may be toxic. This toxicity becomes more apparent in case of $\mathrm{H}_{2} \mathrm{PtCl}_{6}$ salt that shows conspicuous mortality to cells at both 50 and $100 \mu \mathrm{M}$ of salt concentration. Gratifyingly, the results with BSA capped Ag-Pt alloy NPs are very encouraging with viability of $100 \%$ at both, 50 and $100 \mu \mathrm{M}$ concentrations. Additionally, since viability was negligible in Pt salt precursor, we choose silver salt precursor and $\mathrm{Ag}-\mathrm{Pt}$ alloy nanoparticles for comparative study of proliferation kinetics at
$50 \mu \mathrm{M}$ concentrations. Cells were inoculated with suitable seeding density and counted after every $24 \mathrm{~h}$ (Fig. 4B). The results indicate that cells proliferate better in BSA capped Ag-Pt environment compared to control (cells without any salt precursor or alloy NPs) and silver salt environment. This may occur due to size dependent faster uptake of protein capped alloy nanoparticles and the protein uptake subsequently may activate certain growth factors that are necessary for cell proliferation in vitro. It is note worthy that after 6 days of kinetics proliferation differences increases clearly.

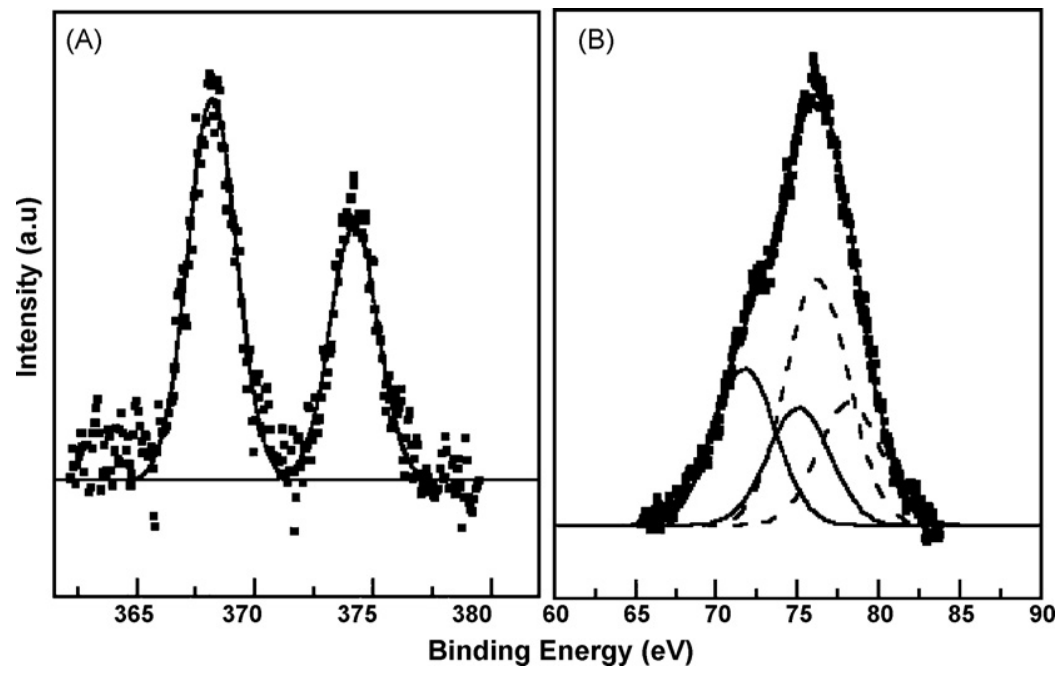

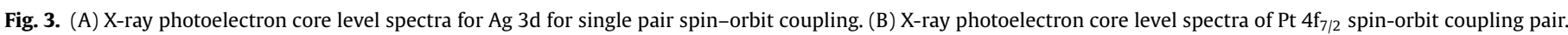
The solid lines corresponds to $\mathrm{Pt}_{4} \mathrm{f}_{7 / 2}$ and dashed lines corresponds to $\mathrm{Cu} 3 \mathrm{p}$. The $\mathrm{Cu}$ signals are form the substrate.

Please cite this article in press as: A.V. Singh, et al., Synthesis of Ag-Pt alloy nanoparticles in aqueous bovine serum albumin foam and their cytocompatibility against human gingival fibroblasts, Colloids Surf. B: Biointerfaces (2009), doi:10.1016/j.colsurfb.2008.11.021 

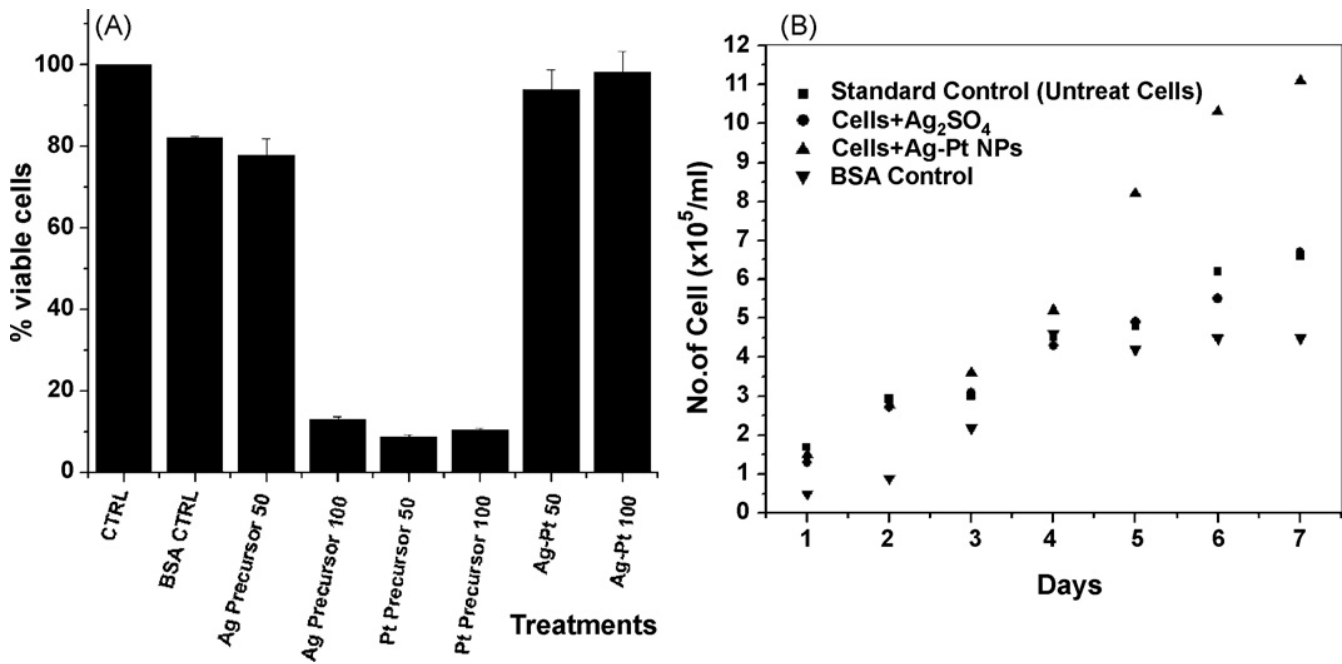

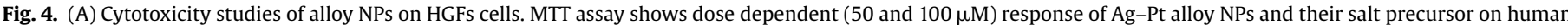
gingival fibroblast after $24 \mathrm{~h}$ of exposure. (B) Cell proliferation assay performed during 7 days on cells in vitro with alloy and salt precursor.

We also addressed another important issue regarding inherent detoxification mechanism of cells in vitro that may explain the results observed above. The primary fibroblast culture that we started our experiments with, are expected to have some degree of inherent detoxification mechanism to the toxicity of metals [27]. We tried to understand the detoxification mechanism both at protein and mRNA level. In general, expression of metallotheonein, a low molecular weight, cysteine rich, metal binding protein is known to facilitate biocompatibility of various metal ions to cells in vitro [17] though the precise mechanism is yet to be explored. It is hypothesized that MT binds to metal precursors in medium bring- ing a reduction in the toxic potential of metals. We evaluated the expression of metallotheonein protein in cell culture experiments by ELISA in presence of salt precursor and alloy NPs. It is observed that neither the control cells (untreated) nor the cells exposed to platinum salt precursor in 50 and $100 \mu \mathrm{M}$ concentrations express MT (Fig. 5A, columns 4 and 5 respectively). This is to be expected to some extend because silver ions are known to be toxic. Luckily the expressed MT is probably reducing their toxicity and making them biocompatible. What is interesting is that $\mathrm{Pt}^{4+}$ ions, which are probably not as toxic as that as $\mathrm{Ag}^{+}$ions, do not elicit the MT expression and the cell viability is significantly low in this case. On the other
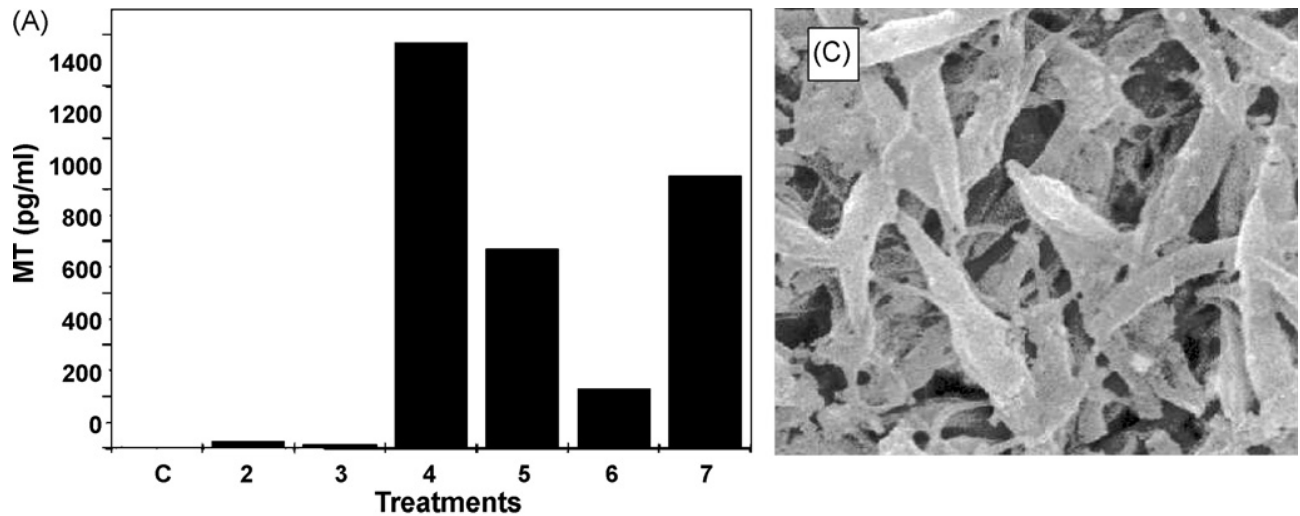

(B)
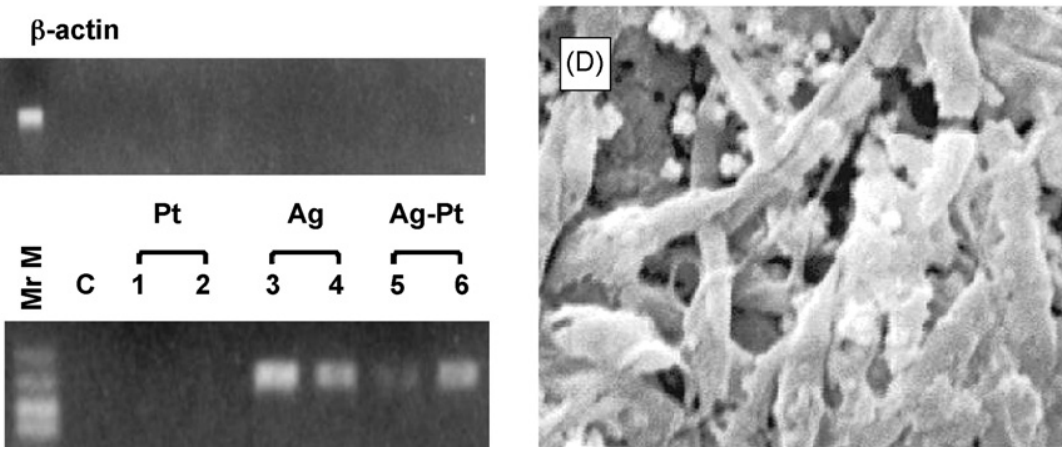

Fig. 5. (A) ELISA showing MT expression after cell exposure to salt precursor and alloy NPs (C: control; Pt salt: 2 and 3; silver salt: 4 and 5 ; alloy NPs correspond to plots 6 and 7 respectively). Plots 2, 4 and 6 correspond to $50 \mu \mathrm{M}$ and 3,5, 7-100 $\mu \mathrm{M}$ concentrations. (B) RT-PCR data showing production of MT at mRNA level (upper panel: $\beta$-actin as loading control; lower panel: $\mathrm{Mr} \mathrm{M}$, molecular marker; C, control; 1,3 and 5 correspond to $50 \mu \mathrm{M}$ and 2, 4, 6-100 $\mu \mathrm{M}$ concentration respectively). (C and D) SEM images from cells exposed to $100 \mu \mathrm{M}$ silver salt and alloy NPs respectively.

Please cite this article in press as: A.V. Singh, et al., Synthesis of Ag-Pt alloy nanoparticles in aqueous bovine serum albumin foam and their cytocompatibility against human gingival fibroblasts, Colloids Surf. B: Biointerfaces (2009), doi:10.1016/j.colsurfb.2008.11.021 
hand, both silver salt and Ag-Pt alloy NPs (columns 4 and 5: Ag salts; columns 6 and 7: alloy NPs) elicit significant MT expression that probably make them biocompatible. However, these results are little more complex to be explained in simple term and probably need to be studied at much detailed level. These will be addressed in our future work.

In addition, we evaluated expression of MT genes in relation with protein profile studies as above. Interestingly, mRNA expression data obtained by RT-PCR supports the above observations in ELISA test (Fig. 5B). Untreated cells taken as control and cells treated with Pt salt precursor show no expression of mRNA, as MT expression at protein level is absent. MT expression is vivid in wells with fibroblast exposed to silver salt precursor. Moreover, since there is nominal MT expression in cells treated with BSA capped Ag-Pt alloy NPs, in mRNA profile an under expressed faint band is observed. Thus ELISA result are in reasonably good agreement with the RT-PCR results corroborating that $\mathrm{Ag}-\mathrm{Pt}$ alloy NPs do not elicit toxic effects even at concentrations up to $100 \mu \mathrm{M}$ though their counter part platinum salt precursor imposed severe toxicity. Also, it is gratifying to see that the cell proliferation is significantly higher in the presence of alloy NPs. These results demonstrate that alloy NPs synthesized in BSA foam is promising candidates for dentistry and prosthetic applications in vivo. Also, SEM images (Fig. 5C and D) demonstrate that cells remain intact showing survival after incubation with alloy NPs while the cells loose surface integrity with the Pt salt.

In conclusion, the unique foam forming properties of BSA protein has been adeptly exploited to synthesize Ag-Pt alloy nanoparticles. In addition, we presented detailed study regarding cytocompatibility and detoxification of these alloy NPs to HGFs that suggest NPs do not alter cell morphology and rate of proliferation of cells in vitro. The tissue permeability and nontoxic nature of alloy demonstrate their promising applications in as dental prosthetic/restorative materials. We believe that the biocompatible alloy NPs using BSA protein foam template will raise sufficient interest as novel materials for dentistry and prosthesis applications. Further work in this direction is currently in progress.

\section{Acknowledgements}

The authors thank the Department of Biotechnology (DBT), govt. of India for financial support. We acknowledge A.B. Gaikwad, Cen- tre for Materials Characterization, NCL, Pune for SEM assistance. We also thank Dr. S. Krishna, Senior Resident in Dental OPD, KEM Hospital, Pune for providing the HGF primary cells.

\section{References}

[1] K.J. Klabunde, in: K.J. Klabunde (Ed.), Nanoscale Materials in Chemistry, Wiley, New York, 2002 (Chapter 1).

[2] N. Sounderya, Y. Zhang, Recent Patents Biomed. Eng. 1 (2008) 34.

[3] J. Kim, J.E. Lee, J. Lee, J.H. Yu, B.C. Kim, K. An, Y. Hwang, C.-H. Shin, J.-G. Park, J. Kim, T. Hyeon, J. Am. Chem. Soc. 128 (2006) 688.

[4] I.S. Lee, N. Lee, J. Park, B.H. Kim, Y.-W. Yi, T. Kim, T.K. Kim, I.H. Lee, S.R. Paik, T. Hyeon, J. Am. Chem. Soc. 128 (2006) 10658.

[5] H. Kim, M. Achermann, L.P. Balet, J.A. Hollingsworth, V.I. Klimov, J. Am. Chem. Soc. 127 (2005) 544.

[6] (a) K. Chung, L. Hsiao, Y. Lin, J. Duh, Acta Biomater. 4 (2007) 717; (b) Singi Co. Ltd., Japan claims its Apagard ${ }^{\circledR}$ range of products contain hydroxyapatite nanoparticles that fill the cavities in teeth.

[7] S. Ramkrishna, J. Mayer, E. Wintermantel, K.W. Leong, Compos. Sci. Technol. 61 (2001) 1189.

[8] L.C. Lucas, J.E. Lemons, Adv. Dent. Res. 6 (1992) 32

[9] S.M. Dymecky, J. Black, D.S. Nord, S.B. Jones, T.J. Baranowski, C.T. Brighton, J. Orthop. Res. 3 (2005) 125.

[10] M.A. Brook, Biomaterials 27 (2006) 3274.

[11] K. Ono, R. Okuda, Y. Ishii, S. Kamimura, M. Oshima, J. Phys. Chem. B 107 (2003) 1941.

[12] H.-P. Liang, Y.-G. Guo, H.-M. Zhang, J.-S. Hu, L.-J. Wan, C.-L. Bai, Chem. Commun. (2004) 1496.

[13] S. Link, Z.L. Wang, M.A. El-Sayed, J. Phys. Chem. B 103 (1999) 3529.

[14] A.V. Singh, B.M. Bandgar, M. Kasture, B.L.V. Prasad, M. Sastry, J. Mater. Chem. 15 (2005) 5115.

[15] J. Chen, B. Wiley, J. McLellan, Y. Xiong, Z.Y. Li, Y. Xia, Nano. Lett. 5 (2005) 2058.

[16] R. Von Noort, Introduction to Dental Materials, 3rd ed., Elsevier, Amsterdam, 2007.

[17] J. Liu, W.C. Kershaw, C.D. Klaassen, Toxicol. Appl. Pharmacol. 107 (1991) 27

[18] D.A. Shirley, Phys. Rev. B 5 (1972) 4709.

[19] J. Valderrama, A. Rodriguez, M.J. Gálvez-Ruiz, R. Miller, D. Langevin, M.A. Cabrerizo-Vílchez, Colloids Surf. A 323 (2007) 116.25

[20] P. Mulvaney, Langmuir 12 (1996) 788.

[21] J.A. Creighton, D.G. Eadon, J. Chem. Soc., Faraday Trans. 1 (87) (1991) 3881.

[22] K. Torigoe, Y. Nakajima, K. Esumi, J. Phys. Chem. 97 (1993) 8304.

[23] A.B. Smetana, K.J. Klabunde, C.M. Sorensen, A.A. Ponce, B. Mwale, J. Phys. Chem. B 110 (2006) 2155.

[24] B.D. Cullity, Elements of X-ray Diffraction, 3rd ed., Wiley, 2001

[25] D. Briggs, M.P. Seah (Eds.), Practical Surface Analysis-By Auger and X-ray Photoelectron Spectroscopy, John Wiley \& Sons, Chichester, 1990.

[26] T. Mosmann, J. Immunol. Methods 95 (1993) 55.

[27] J.C. Wataha, C.T. Hanks, Z. Sun, Dent. Mater. 10 (1994) 156. 